Research Article

\title{
Mobile Information Systems Usage and Doctor-Patient Relationships: An Empirical Study in China
}

\author{
Xin Zhang, ${ }^{1,2,3}$ Liang Ma $\mathbb{D}^{1},{ }^{1}$ Yanbo Ma, ${ }^{1,2}$ and Xiao Yang ${ }^{1,2}$ \\ ${ }^{1}$ School of Management Science and Engineering, Shandong University of Finance and Economics, Jinan, China \\ ${ }^{2}$ Shandong Engineering Laboratory for Wisdom Endowment and Big Data, Jinan, China \\ ${ }^{3}$ Big Data Collaborative Innovation Center of "Internet + Medical Care and Health", Jinan, China
}

Correspondence should be addressed to Liang Ma; maliang1010@126.com

Received 15 December 2020; Revised 9 February 2021; Accepted 13 April 2021; Published 27 April 2021

Academic Editor: Ding Xu

Copyright (c) 2021 Xin Zhang et al. This is an open access article distributed under the Creative Commons Attribution License, which permits unrestricted use, distribution, and reproduction in any medium, provided the original work is properly cited.

How to improve the doctor-patient relationship has been a continuing topic in academia and management and there have been several attempts to utilize online communications to facilitate healthcare. The application of information technology to create an "Internet + medical care" platform has upended the traditional medical service model in China. As an example of the application of the Internet by the healthcare system, this paper investigates a mobile online appointment system used by hospitals. Data on system use came from questionnaires submitted by 225 patients and analyzed by the structural equation model method. The results showed that patients perceived the hospital's online appointment system as an attempt at transparency to which they reacted positively. The patients' perception of transparency promoted trust in the hospital and the doctors and positively affected their feelings of satisfaction, which, of course, improved the doctor-patient relationship. Patients' perceptions of transparency, trust in the hospitals and doctors, and feelings of satisfaction played a partial mediator role between the availability of an online appointment system and better doctor-patient relationships. There were significant gender differences among patients in terms of their feelings of trust and satisfaction with the new appointment method and whether it really improved the doctorpatient relationship.

\section{Introduction}

In recent years, there have been many problems with the doctor-patient relationship in China. The number and severity of doctor-patient conflicts, disputes, and disturbances have been increasing and trust in the doctorpatient relationship has steadily declined [1]. Academic and management researchers now struggle to decide how best to improve the patient's medical experience and regain their trust and satisfaction. Advances in information technology as applied to Internet medical treatment not only facilitate medical reform, but also bring much-needed change in traditional modes of medical service. According to the 2018 China Internet development report, the number of Internet medical users in China reached 253 million by December 2017, an annual increase of $29.7 \%$, and in the next few years, the average annual compound growth rate of China's Internet medical will reach $55.01 \%$, and the scale of China's mobile medical market will reach 697.4 billion RMB in 2021 [2]. One of the outcomes of the integration of the Internet and the medical industry was the deployment of online appointment registration. Compared to traditional appointment making (in person, by telephone, etc.), the Internet method is not limited by time or place, which saves time and cost, improves hospital service efficiency, reduces overcrowding, shortens waiting times, and improves patients' hospital experience. However, many questions still exist. How will the online booking system affect patients? Will the use of online appointments affect the doctor-patient relationship? What intermediate mechanisms and boundary conditions exist? So far, no clear conclusions have been drawn. Clarifying the effects of being able to make and keep track of appointments 
online is of great significance to the implementation of hospital information systems and for helping doctors and patients get along better.

The existing research on the quality of the relationship between doctors and their patients has mainly focused on four aspects: (1) the nature of the relationship between doctors and patients $[3,4] ;(2)$ the investigation and study of doctor-patient relationships [5]; (3) the factors influencing the doctor-patient relationship $[6,7]$; and (4) the countermeasures employed in doctor-patient relationship [8]. Some scholars have investigated the impact of hospital information systems on the doctor-patient relationship [6] and patient satisfaction [9] but most existing studies have looked at doctor-patient relationships from the perspective of perceived fairness [6] and service quality [9]. Few studies have been done to explore how an improvement like online appointment making might influence how patients feel about their doctors and whether they trust them more. Generally, the adoption and use of emerging technology will have a certain impact on patients' cognition, perceptions, attitude, and even the level of trust [10-13]. The electronic appointment system has some unique characteristics, and how they affect the patients' perceptions of trust, satisfaction, and relation to their doctor so far has not been determined. Existing research has focused on the mechanism and path of hospital information system deployment, but few studies have examined the boundary conditions of hospital information system function, and most have ignored the influence of gender on using electronic appointment registration systems.

Therefore, to fill these research gaps, this paper utilized the trust theory to determine the effects of online appointment making on the improvement of the doctor-patient relationship. In addition, the influence of gender on the use and responses to the system was also examined. This paper enriches the scope of trust theory research, and the conclusions deepen our understanding of how a relatively simple improvement like being able to make an appointment online might have far-reaching effects on patients' trust in the hospital system and their doctors. From a practical point of view, the research conclusions of this paper can provide beneficial references for the implementation of hospital information systems and improvement of the doctor-patient relationship.

\section{Theoretical Basis and Research Hypotheses}

2.1. Trust Theory. In the field of management, trust is defined as "a psychological state that is willing to expose weaknesses, which is based on the trust's positive expectation of the intention and behavior of the trusted, that is, the future intention and behavior of the trusted will not harm the interests of the trusted" [14]. According to other standards, trust can be divided into situational trust and quality trust [15]. Situational trust depends only on the characteristics of the environment and is independent of the other party's attributes. Quality trust indicates that different trading partners have different standards of conduct, fairness, and moral commitment, which will give them different credibility. Mayer et al. [16] divided quality trust into three dimensions: competence trust, goodwill trust, and integrity trust. Trust is an effective variable in reducing uncertainty [17] and with the emergence of the Internet in recent years, trust has attracted more and more attention [18]. Trust in relation to the Internet can be divided into two types: trust in platform and trust in service provider [19]. In the field of medical treatment, this study divided patients' trust into trust in hospital and trust in doctor by referring to previous studies. Among them, trust in the hospital refers to the patient's belief that the hospital will perform all its services in an exemplary manner. Trust in doctors includes feelings about competence, integrity, and goodwill.

This study explored the effect of a specific electronic appointment system where only a doctor's professional title and specialty can be seen on the appointment page. Therefore, doctors' trust in this study mainly refers to patients' trust in doctors' abilities. In academic circles and in the medical field, patients' trust has always been a hot topic. More and more studies have discussed the factors influencing patients' trust and how trust, or lack thereof, can alter people's perceptions of the hospital experience. Existing studies have found that perceived risks and perceived benefits and trust in hospitals and doctors are important factors influencing patients' trust $[20,21]$, while patients' trust is an important factor influencing the doctor-patient relationship and patient satisfaction [22, 23]. Taking an online appointment system as an example, this study will explore the antecedents and effects of patients' trust based on trust theory.

2.2. Online Appointment System. With the integration of the Internet and healthcare services, China's major hospitals have launched online appointment and registration services on their official websites. Mobile medical apps and WeChat public accounts have also launched relevant services [24]. Compared with traditional appointment (on-site appointment, telephone appointment, etc.), online appointment is not limited by time and place, which can save time and cost, reduce the overcrowding in the outpatient department of the hospital, and improve the patients' medical experience. However, online appointment making is a relatively new technology and research on the effect of online appointment system use is scarce. Research on the implementation of hospital information systems has been done, but it mainly focused on only a few aspects. Initial studies measured how quickly patients adopted the new systems [25]. For example, based on the technology acceptance model, Chang et al. [26] found that ease of use, perceived usefulness, website quality, and service quality all contributed to an individual's intention to use the system. Handayani et al. [27] found that human characteristics, technical characteristics, and organizational characteristics affected the perceived ease of use and usefulness of the system and thus affected the user's adoption of the hospital information system.

The second focus was on the impact of the hospital information system on patients and doctors. For example, 
Venkatesh et al. [9] found that the use of hospital information systems affected patient satisfaction because of technical quality, interpersonal communication, and time consumption. Based on data from 229 patients, Liang et al. [6] found that the implementation of a hospital information system affected patient satisfaction and the improvement of doctor-patient relationship by changing the patients' perceptions of fairness. The traditional offline hospital registration often resulted in queue-jumping and acquaintance registration, which caused patients to distrust hospital information and lodge complaints against hospitals and doctors. The online appointment system can connect patients with doctors, register the appointment times, provide registration procedures, and list the doctor's areas of expertise. To some extent, the use of an online appointment system can reduce the occurrence of queue-jumping and acquaintance registration, and patients can also see the appointment time and price of the doctor, which perceive more fairness, which will increase patients' perception of the transparency of hospital registration. Based on the above, this paper proposes the following hypothesis:

H1: The use of an online appointment system positively affects patient's perceptions of transparency.

\subsection{Perceived Transparency and Trust. Perceived trans-} parency is defined as "preparing to release information required by law, including positive and negative information, while the information disclosed is clear, complete, accurate, and reliable to improve the public's reasoning and behavior ability" [28]. Trust theory considers transparency an important driver of trust [29] that includes the following characteristics: information accessibility, timely disclosure, comprehensibility, relevance and usefulness, accuracy, and reliability. Perceived transparency in this paper refers to the accessibility, timely openness, comprehensibility, relevance and usefulness, accuracy, and reliability of hospital-registered information perceived by patients. Some investigators have focused on the transparency of drug prices $[30,31]$, perceived value and satisfaction [32], medical decision-making [33], and other areas [34]. For example, Palanski et al. [35] found that team transparency in enterprise start-ups positively influenced team integrity and trust. Auger [36] proved that organizations demonstrating transparency achieved more than twice the levels of trust and positive behavioral intentions than organizations that demonstrated neither type of transparency. With the growing use of the Internet by the medical industry, China's major hospitals have launched online appointment services that are more transparent and public. Referring to trust theory, this paper argues that when hospital registration information is more open and transparent, patients' trust in hospitals and doctors will increase. Based on the above, this paper proposes the following hypotheses:

H2: Perceived transparency positively affects patients' trust in hospitals.

H3: Perceived transparency positively affects patients' trust in doctors.
2.4. Trust, Satisfaction, and Doctor-Patient Relationship Improvement. This paper considers two areas of patients' trust: in hospitals and in doctors [37]. It is a truism that trust is an important precondition for satisfaction $[38,39]$ and even more so in healthcare $[40,41]$. When patients have trust in hospitals and doctors, they are more likely to have positive attitudes and emotions [42] and thus more likely to be satisfied. Based on the above, this paper hypothesizes that trust in hospitals and doctors positively affects patient satisfaction. The appropriate application of new technologies in hospitals should improve doctor-patient relations [43, 44], especially with regard to information systems because better communication increases satisfaction with their medical care [45]. Venkatesh et al. [9] found that the use of hospital information systems affected patient satisfaction through influencing technical quality, communication, interpersonal communication, and time usage. Previous studies have confirmed that trust and satisfaction are the most important factors influencing the doctor-patient relationship [46, 47]. For example, based on data from 229 patients, Liang et al. [6] found that people were more satisfied with the service when their hospital put in an electronic information system. Not surprisingly, Faezipour and Ferreira [48] found that happy patients complained less and said they enjoyed good rapport with their doctors. Based on the above, this paper assumes that patient satisfaction positively improves the doctorpatient relationship and proposes the following hypotheses:

H4: patients' trust in hospitals positively affects patient satisfaction.

H5: patients' trust in doctors positively affects patient satisfaction.

H6: patient satisfaction positively influences the improvement of doctor-patient relationships.

Based on the above discussion, this paper proposed a working model as shown in Figure 1. In particular, the use of an online appointment system reduces the occurrence of queue-jumping and acquaintance registration, and patients can also see the appointment time and price of the doctor, which perceive more fairness, which thus positively affects patients' perceptions of transparency. When patients perceive transparency, their trust in hospitals and doctors will also increase, which further influences patient satisfaction and the improvement of doctor-patient relationships.

\section{Study Design}

This study adopted a hybrid method with a questionnaire and interviews. The reason is that, on the one hand, the use of qualitative research can obtain richer data and observe the laws of the phenomenon; on the other hand, it gives researchers more room for interpretation, exerts creativity, and makes up for the deficiencies of quantitative research. This paper explored qualitatively using interviews to determine the patients' experiences with the system and whether it increased trust of the hospital and the doctors. The research was limited to users of the online appointment system. First, users' feelings towards the online appointment system were determined qualitatively through interviews. The initial structure of the questionnaire was 


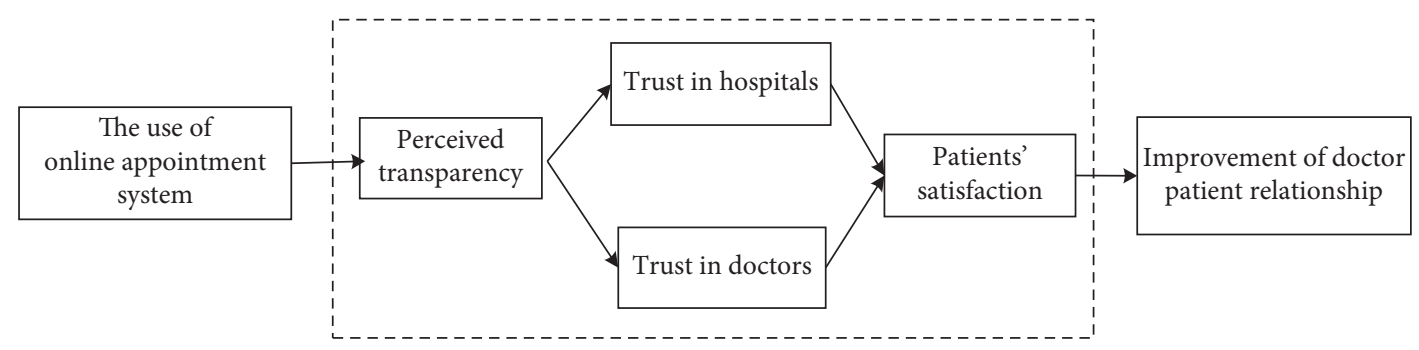

FIgURE 1: Research model.

arrived at through a comprehensive literature review. Secondly, the initial questionnaire was sent to those who used the system for improvement and modification, and finally, the questionnaires were collected through multiple channels.

3.1. Qualitative Research Based on Interviews. The online appointment system was first explored qualitatively using interviews to determine the patients' experiences with the system and whether it increased trust of the hospital and the doctors. The interviewees were two associate professors and a graduate student familiar with the online appointment system and the interviews each lasted about 45 minutes. The interview questions are as follows: What impact do you think the implementation of the online appointment system will have on patients and doctors? Do you think the implementation of the online appointment system will affect the matching of doctors and patients? If so, then how will it affect doctor-patient matching? Do you think the implementation of the online appointment system will affect the doctor-patient relationship? If so, then in what ways will it have an impact? What do you think the online appointment system can be improved?

Through the interview, the following findings were attained: for patients, the online appointment system provides convenience for patient registration. Patients can query the information of doctors in the system for registration, increase the matching between doctors and patients, and increase fairness and transparency to a certain extent; when patients use the system to register, being able to understand the doctor's professional title and expertise in information is conducive to increasing the trust of patients in doctors; patients often have a higher success rate through registration, thereby reducing unnecessary round-trip and travel expenses and increasing their satisfaction. When patient satisfaction is high, the doctor-patient relationship with doctors is improved. For doctors, they can utilize the online appointment system to enhance their service quality and increase their performance. At the same time, the interviewer suggested that the online appointment registration system can increase the function of patients' comments on doctors, and the interface should be much simpler and convenient for the elderly to operate. The understanding of the research phenomenon was improved through the interviews, and the interviewers were better able to focus on the questions. The results provided the basis for the extraction of constructs, research model construction, and scale correction.
3.2. Measurement of Variables. The study questionnaire consisted of two parts. The first acquired the individuals' demographic data, including gender, age, education, and economic status. The second part was designed to measure each variable in the theoretical model. In order to ensure validity, the questionnaire was designed around verified scales from domestic and foreign studies. Those measures are shown in Table 1. There were three measurement items related to the online appointment system (SU), for example: "When I go to the hospital, I use the online appointment system." The scale was selected from the mature scale of Liang et al. [6]. Perceived transparency (TM) had two measured items: "With the implementation of the online appointment system, I think hospital registration is more open and transparent." The scale was adapted and revised from the scale of Liang et al. [6] and Norman et al. [34]. Trust in hospital (TH) consisted of three measurement questions, represented by: "The hospital where I go for treatment is trustworthy based on my experience." The scale was selected from the mature scale of Gefen et al. [49]. A patient's trust in a doctor (TD) mainly refers to their perception of the doctor's ability. The questionnaire contained three question items, for example: "The doctor I chose is competent." The scale was selected from the mature scale of Mcknight et al. [50]. Patient satisfaction (PS) was measured by the question: "Are you satisfied with the doctor's service when you seek medical treatment?" [51]. The improvement of doctor-patient relationship (YH) consists of three measurement questions, which are measured by the question item: "With the implementation of an online appointment system, I feel that the doctor-patient relationship is not as tense as before." The scale was selected from the mature scale of Liang et al. [6]. The questionnaire was in the form of a 7-level Likert scale, with 1 indicating great disagreement and 7 indicating great agreement. After the scale design was completed, the enterprise manager of the online appointment system and an associate professor familiar with the use of the online appointment system were respectfully invited to complete and revise the questionnaire. After the modification, the questionnaires were distributed.

3.3. Data Collection. This study adopted a multisource data collection method. First, the questionnaire was published on the Shandong service platform of medical union, and users were invited to fill out the questionnaire and submit the data. The Shandong service platform of medical union is a public service platform for medical care and health embedded in 
TABle 1: Measurement items.

\begin{tabular}{|c|c|}
\hline Constructs & Measure items \\
\hline Online appointment system use(SU) & $\begin{array}{l}\text { I Frequently used the online appointment system in the hospital in my previous visits to the } \\
\text { hospital. } \\
\text { Without the online appointment system, my hospital visits will be inconvenient. } \\
\text { Other patients I know are also using the online appointment system. }\end{array}$ \\
\hline Perceived transparency (TM) & $\begin{array}{c}\text { With the implementation of online appointment system, I think hospital registration is more } \\
\text { open and transparent } \\
\text { With the implementation of online appointment system, I think the hospital registration is more } \\
\text { open and transparent than before }\end{array}$ \\
\hline Trust in hospital (TH) & $\begin{array}{l}\text { Based on my experience, I think the hospital I chose is credible } \\
\text { Based on my experience, I think the hospital I chose cares about patients } \\
\text { Based on my experience, I think the hospital I chose is trustworthy }\end{array}$ \\
\hline Trust in a doctor (TD) & $\begin{array}{l}\text { The doctor I see is competent } \\
\text { The doctor I see can do his duty well } \\
\text { The doctor I see knows how to provide good service }\end{array}$ \\
\hline Patient satisfaction (PS) & When you go to the hospital, are you satisfied with the doctor's service? \\
\hline $\begin{array}{l}\text { Improvement of doctor-patient } \\
\text { relationship }(\mathrm{YH})\end{array}$ & $\begin{array}{l}\text { With the implementation of the online appointment system, I feel I have fewer complaints about } \\
\text { the hospital. } \\
\text { With the implementation of the online appointment system, I feel the hospital has fewer disputes } \\
\text { with patients. } \\
\text { With the implementation of the online appointment system, I feel the patient-doctor relationship } \\
\text { is as not as tense as before. }\end{array}$ \\
\hline
\end{tabular}

the WeChat public account, which is built and operated by the Shandong Shuneng Network Technology Co., Ltd. based on the mobile Internet. At present, the platform has been connected to more than twenty key provincial third-level hospitals, including Provincial Hospital, Qilu Hospital, and Qian Foshan Hospital in Shandong province. The platform uses mobile Internet terminals as carriers and applies the latest distributed architecture. To ensure independent operation of the hospital system, the platform connects to the hospital information system in real time through the network via information interconnection and interworking. The platform can provide full medical service for the optimization of offline diagnosis and treatment, covering such functions as intelligent guidance, appointment registration, recharge payment, report inquiry, and health consultation. We collected 40 questionnaires and two of these were rejected because the respondent had not used the online appointment registration platform, which left 38 valid questionnaires.

Secondly, questionnaires were collected by the snowball method. Unlike random sampling methods, the snowball method is used to collect reasonably representative data in the different districts because they would have been hard to access. Considering the collection of reasonably representative data in a different district and the difficulty of data collection, this study used the snowball method. The author set as the first seeds of the snowball sample recruited. The criterion is that participants must have used the online appointment system and still use it now. We published the questionnaire link in a Friend Circle and a WeChat group for data collection, and 75 questionnaires were collected. Twenty of these were deleted because they did not use the online appointment registration platform, leaving 55. Thirdly, 200 questionnaires were issued on the professional Internet platform (Soujump.com), and 52 questionnaires were excluded as not using the online appointment registration platform, leaving 148 questionnaires. At the end, a total of 241 questionnaires were collected, and 16 were rejected because the respondent had spent less than five minutes filling it out. The remaining 225 were considered valid. The questionnaire also collected descriptive statistical characteristics of respondents, such as gender, age, education, income, and choice of doctor. Specific descriptive statistics of respondents are shown in Table 2 below.

\section{The Empirical Test}

4.1. Reliability and Validity Analysis. The reliability test results of Smart PLS 2.0 analysis are shown in Table 3. First, this study conducted construct validity, which included convergent validity and discriminant validity. In particular, convergent validity can be accessed by AVE and CR, and discriminant validity can be accessed by the comparison of the correlation coefficient and AVE square root values of the measured variables. The standard loading of all measurement terms was above 0.5 , and the average extraction variance (AVE) of each latent variable was greater than 0.5 . The $\mathrm{CR}$ values of the complex reliability of each latent variable were all greater than 0.7 , meaning that the measurement model was internally consistent. Thus, the AVE and $\mathrm{CR}$ value indicate that the scale had good convergence validity. Meanwhile, from the operation results of Smart PLS, the correlation coefficient and AVE square root values of the measured variables are as shown in Table 3. It can be seen that the AVE square root values were all larger than the correlation coefficient between the measured variables, showing good discrimination validity of the scale. The Cronbach alpha coefficient of all latent variables was greater than 0.7 , indicating that the scale was reliable.

Finally, the factor loading and cross-factor loading of the measurement item are given in Table 4 . The factor loading of all variables was greater than 0.5 and significant at the 0.001 
Table 2: Descriptive statistics of respondents.

\begin{tabular}{|c|c|c|c|}
\hline Items & Classification & Number & $\%$ \\
\hline \multirow{2}{*}{ Sex } & Male & 96 & 42.67 \\
\hline & Female & 129 & 57.33 \\
\hline \multirow{5}{*}{ Age } & $<20$ years old & 5 & 2.22 \\
\hline & $20-29$ years old & 93 & 41.33 \\
\hline & $30-39$ years old & 91 & 40.44 \\
\hline & 40-49 years old & 27 & 12.00 \\
\hline & $\geq 50$ years old & 9 & 4.00 \\
\hline \multirow{4}{*}{ Education } & High school and below & 7 & 3.11 \\
\hline & Specialized subject & 35 & 15.56 \\
\hline & Undergraduate course & 129 & 57.33 \\
\hline & Master degree or above & 54 & 24.00 \\
\hline \multirow{5}{*}{ Income (RMB) } & $<3000$ & 21 & 9.33 \\
\hline & $3001-5000$ & 42 & 18.67 \\
\hline & $5001-8000$ & 96 & 42.67 \\
\hline & $8001-12000$ & 52 & 23.11 \\
\hline & $>12000$ & 14 & 6.22 \\
\hline \multirow{4}{*}{ Choose doctors } & Chief physician (senior) & 7 & 3.11 \\
\hline & Deputy chief physician (deputy senior) & 35 & 15.56 \\
\hline & Attending physician (intermediate) & 129 & 57.33 \\
\hline & Resident physician (junior) & 54 & 24.00 \\
\hline
\end{tabular}

TABLE 3: Reliability and validity.

\begin{tabular}{lccccccccc}
\hline Items & CR & Alpha & AVE & SU & TM & TD & TH & PS & YH \\
\hline SU & 0.824 & 0.700 & 0.611 & $\mathbf{0 . 7 8 2}$ & & & & \\
TM & 0.851 & 0.662 & 0.742 & 0.389 & $\mathbf{0 . 8 6 1}$ & & & \\
TD & 0.907 & 0.846 & 0.765 & 0.391 & 0.556 & $\mathbf{0 . 8 7 5}$ & 0.681 & $\mathbf{0 . 8 9 6}$ & \\
TH & 0.925 & 0.878 & 0.803 & 0.395 & 0.578 & 0.581 & 1.000 \\
PS & 1.000 & 1.000 & 1.000 & 0.310 & 0.423 & 0.624 & 0.584 & 0.394 \\
YH & 0.914 & 0.859 & 0.780 & 0.372 & 0.642 & 0.526 & $\mathbf{0 . 8 8 3}$ \\
\hline
\end{tabular}

Note. SU: use of online appointment system; TM: perceived transparent; TD: trust in doctors; TH: trust in hospital; PS: patient satisfaction; YH: doctor-patient relationship improvement.

TABLE 4: Factor loading and cross-factor loading.

\begin{tabular}{lcccccc}
\hline Items & SU & TM & TD & TH & PS & YH \\
\hline SU1 & $\mathbf{0 . 7 3 4}$ & 0.215 & 0.233 & 0.318 & 0.288 & 0.167 \\
SU2 & $\mathbf{0 . 7 4 9}$ & 0.245 & 0.248 & 0.211 & 0.213 & 0.198 \\
SU3 & $\mathbf{0 . 8 5 7}$ & 0.400 & 0.391 & 0.375 & 0.245 & 0.425 \\
TM1 & 0.230 & $\mathbf{0 . 8 0 6}$ & 0.356 & 0.447 & 0.263 & 0.520 \\
TM2 & 0.413 & $\mathbf{0 . 9 1 3}$ & 0.572 & 0.541 & 0.440 & 0.585 \\
TD1 & 0.326 & 0.522 & $\mathbf{0 . 8 8 0}$ & 0.602 & 0.538 & 0.505 \\
TD2 & 0.349 & 0.442 & $\mathbf{0 . 8 8 7}$ & 0.615 & 0.538 & 0.406 \\
TD3 & 0.351 & 0.491 & $\mathbf{0 . 8 5 7}$ & 0.571 & 0.560 & 0.465 \\
TH1 & 0.361 & 0.569 & 0.591 & $\mathbf{0 . 8 9 0}$ & 0.518 & 0.597 \\
TH2 & 0.294 & 0.460 & 0.611 & $\mathbf{0 . 9 1 3}$ & 0.556 & 0.505 \\
TH3 & 0.406 & 0.522 & 0.631 & $\mathbf{0 . 8 8 6}$ & 0.488 & 0.463 \\
PS & 0.310 & 0.423 & 0.624 & 0.581 & $\mathbf{1 . 0 0 0}$ & 0.394 \\
YH1 & 0.362 & 0.624 & 0.509 & 0.534 & 0.341 & $\mathbf{0 . 8 6 7}$ \\
YH2 & 0.305 & 0.537 & 0.409 & 0.489 & 0.357 & $\mathbf{0 . 8 9 0}$ \\
YH3 & 0.321 & 0.543 & 0.477 & 0.526 & 0.346 & $\mathbf{0 . 8 9 3}$ \\
\hline
\end{tabular}

level. The coefficient of correlation between all measured variables and their potential variables was relatively high, while the coefficient of correlation with other latent variables was relatively low, which further indicated that the measurement term had good differentiation and internal consistency.
Before the measurement model analysis, this paper discusses normality, outliers, and common method bias tests. In particular, the normality and outliers showed that all variables obey normal distribution, with no outlier values. To make sure that the dataset is free from common method bias, an inspection of Harman's single factor with six constructs (SU, TM, TD, TH, PS, and TH) was conducted. The statistical results in this respect indicated that no single factor was able to emerge, and the highest covariance explained by one factor is $39.192 \%$, which is less than the cut-off value of $50 \%$. Thus, common method bias is not a serious concern.

4.2. Structural Equation Model Analysis. Smart PLS2.0 was used to test the significance of the relationship between variables (Figure 2). The use of electronic appointment registration positively affected the perceived transparency, so $\mathrm{H} 1$ is supported. Use of the system enhanced patients' perceptions of information openness and transparency. At the same time, the study found that perceived transparency positively affected patients' trust in hospitals and doctors' ability; so $\mathrm{H} 2$ and $\mathrm{H} 3$ are supported. The greater the perceived transparency, the higher the patient's trust in the hospital and the doctor. In addition, patients' trust in 


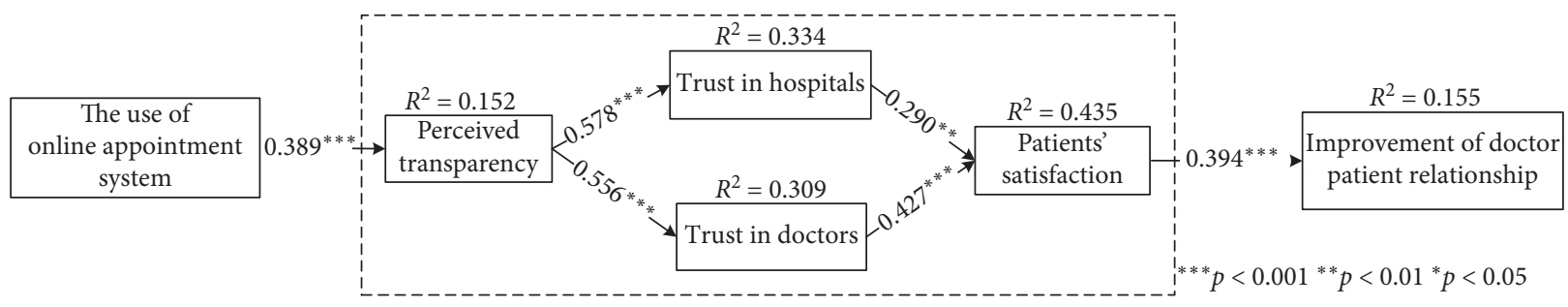

FIGURE 2: Results of structural equation model.

TABLE 5: Mediation effect test.

\begin{tabular}{|c|c|c|c|c|c|c|c|}
\hline \multirow{2}{*}{ IV } & \multirow{2}{*}{$\mathrm{M}$} & \multirow{2}{*}{ DV } & \multirow{2}{*}{ IV-DV } & \multirow{2}{*}{ IV-M } & \multicolumn{2}{|c|}{$(\mathrm{IV}+\mathrm{M})-\mathrm{DV}$} & \multirow{2}{*}{ Effect } \\
\hline & & & & & IV & M & \\
\hline$\overline{\mathrm{SU}}$ & TM & $\mathrm{YH}$ & $0.327^{* *}$ & $0.339^{* *}$ & $0.125^{*}$ & $0.597^{* *}$ & Partial \\
\hline SU & $\mathrm{TH}$ & $\mathrm{YH}$ & $0.327^{* *}$ & $0.377^{* *}$ & $0.126^{*}$ & $0.534^{* *}$ & Partial \\
\hline SU & $\mathrm{TD}$ & $\mathrm{YH}$ & $0.327^{* *}$ & $0.364^{* *}$ & $0.158^{*}$ & $0.467^{* *}$ & Partial \\
\hline SU & PS & $\mathrm{YH}$ & $0.327^{* *}$ & $0.314^{* *}$ & $0.226^{* *}$ & $0.323^{* *}$ & Partial \\
\hline
\end{tabular}

Note. SU: use of registration system; TM: perceived transparent; TD: trust in doctors; TH: trust in hospital; PS: patient satisfaction; YH: doctor-patient relationship improvement; IV: independent variable; M: mediating variable; DV: dependent variable. ${ }^{*} p<0.05,{ }^{* *} p<0.01$.

TABLE 6: Multigroup test results.

\begin{tabular}{lccccccc}
\hline Mediator & Path & PC1 & PC2 & SE1 & SE2 & T & Effect \\
\hline & SU - > TM & $0.36^{* *}$ & $0.44^{* *}$ & 0.09 & 0.09 & -6.32 & Female $>$ Male \\
& TM - > TH & $0.56^{* *}$ & $0.60^{* *}$ & 0.08 & 0.07 & -4.33 & Female $>$ Male \\
Sex (Group1:Male) (Group2:Female) & TM - > TD & $0.61^{* *}$ & $0.53^{* *}$ & 0.06 & 0.07 & 8.97 & Male $>$ Female \\
& TH - > PS & $0.58^{* *}$ & 0.15 & 0.13 & 0.13 & 23.65 & Male $>$ Female \\
& TD - > PS & 0.18 & $0.53^{* *}$ & 0.15 & 0.14 & -17.96 & Female $>$ Male \\
& PS - > YH & $0.51^{* *}$ & $0.30^{* *}$ & 0.10 & 0.10 & 16.09 & Male $>$ Female \\
\hline
\end{tabular}

Note. $S_{\text {pooled }}=\sqrt{\left\{\left[\left(N_{1}-1\right) /\left(N_{1}+N_{2}-2\right)\right] \times S E_{1}^{2}+\left[\left(N_{2}-1\right) /\left(N_{1}+N_{2}-2\right)\right] \times S E_{2}^{2}\right\}}, t=\left(P C_{1}-P C_{2}\right) /\left[S_{\text {Pooled }} \times \sqrt{1 / N_{1}+1 / N_{2}}\right] ; S_{\text {pooled }}=$ pooled estimator for the variance. $t=t$-statistic with $N 1+N 2-2$ degrees of freedom. $N i=$ sample size of dataset for group $i$. SE $i=$ standard error of path in structural model of group i. $P C i=$ path coefficient in structural model of group i. O: support; X: not support. Significance levels: ${ }^{*}, p<0.05$ and ${ }^{* *}, p<0.01$.

hospitals and doctors positively influences patients' satisfaction; so $\mathrm{H} 4$ and $\mathrm{H} 5$ are supported. This suggests that the patient's satisfaction level is directly affected by the patient's trust in the hospital and the doctor. Finally, patient satisfaction positively influences the improvement of the doctorpatient relationship. H6 is supported. This means that patient satisfaction can improve the relationship between doctors and patients. The $\mathrm{R}$ squared value is also given (Figure 2).

4.3. Mediation Effect Analysis. In this paper, the widely accepted Bootstrap method was adopted to examine the mediating effect between the use of electronic appointments and better doctor-patient relationships (Table 5). Firstly, the study found that patients' perceptions of transparency played a partial intermediary role between the use of the online appointment system and the improvement of the doctor-patient relationship. This means that the new appointment system positively influenced the doctor-patient relationship, but this outcome can also come from increased transparency. One explanation is that when patients use an online appointment system, they can see the appointment time and price of the doctor, which perceive more fairness, thereby increasing the perception of transparency and improving the doctor-patient relationship [6]. Second, the patients' trust on hospitals and doctors plays a partial intermediary role between the use of the appointment system and better doctor-patient interactions. Previous studies have confirmed that trust is the most crucial factor influencing the doctor-patient relationship [46, 47]. This paper finds that access to the system breeds trust in the hospital which makes patients feel more comfortable with physicians. Thirdly, patient satisfaction has a partial intermediary effect on use of the appointment system and thereby makes patients and physicians get along better. Prior research has also confirmed that the appropriate application of new technologies in hospitals should improve doctor-patient relations [43, 44], especially with regard to information systems, because better communication increases satisfaction with their medical care [45]. This paper finds that using the online appointment system will promote good feelings between doctors and patients by enhancing patient satisfaction.

4.4. Multigroup Test. This paper used the method of Keil et al. [52] to examine how gender might influence patient perceptions, trust, and satisfaction [53]. The subjects were divided into male and female-96 male and 129 female respondents - and the relationships between the variables 
were examined and tested in this context [54]. The results suggested that women were more likely to have feelings of transparency after using online appointment platforms than men (Table 6). Upon perceiving openness and transparency, male patients were more likely to trust doctors, while female patients were more likely to trust hospitals. Men were more likely to be satisfied when they trusted the hospital, while women were more likely to be satisfied when they trusted their doctors. Finally, the doctor-patient relationship was more likely to be improved among male patients when they said they were satisfied with the healthcare. The discussions can be seen in next part.

\section{Conclusions}

5.1. Key Findings. Based on the trust theory and taking the online appointment system as an example, this paper constructs a model of the use of an online appointment system on patients' trust, satisfaction, and the improvement of the doctor-patient relationship. Through the analysis of data from 225 patients' questionnaires, the followinf was found.

First, the use of online appointment system positively affected patients' perceived transparency. One explanation is that patients can see the appointment time and price of the doctor, which perceive more fairness, thereby increasing the perception of transparency [6]. Patients' perception of transparency positively influenced their trust in hospitals and doctors. One explanation is that, according to trust theory, when hospital registration information is more open and transparent, the trust of patients in hospitals and doctors will increase [29]. Patients' trust in hospitals and doctors positively affected their satisfaction. Prior studies have also proved that trust is an important precondition for satisfaction [55]. Patient satisfaction improved doctor-patient relationships. Liang et al. [6] found that implementation of a hospital information system improved the doctor-patient relationship by affecting patients' perceptions of fairness and satisfaction. By analyzing a popular online health community in China, Li et al. [56] found that the technical quality, interpersonal quality, and eWOM of doctors' medical services positively impact the online follow-up intention of patients. Based on the existing research, this paper further expands upon the use of the online appointment system to show how it affects the patients' perception of transparency, trust, and satisfaction and consequently improves the doctor-patient relationship. At the same time, the study found that there were some mediating effects between the use of online appointment system and the improvement of doctor-patient relationship, such as patient perception of transparency, patients' trust in hospitals and doctors, and patient satisfaction.

Second, the study found that, after using the online appointment system, there were significant gender differences in the perception of transparency, trust of hospitals and doctors, satisfaction, and improvement of doctor-patient relationship. Gender effects have been examined in other studies under different contexts [57-59]. Existing research showed that men and women had different preferences in system usage, risk perception, trust, and behavioral intentions [60-62]. This paper further supported the idea that female patients were more likely to have perceived transparency after using online appointment platforms. When perceiving openness and transparency, male patients were more likely to trust doctors, while female patients were more likely to trust hospitals. One of the possible explanations may be that females are more sensitive to risk, and they are more likely to trust things like hospitals when they are open and transparent [63]. Male patients were more likely to express satisfaction when they trusted the hospital, while females were more likely to feel satisfied when they trusted their doctors. The reason may be that close communication is required between doctors and patients, and females are more emotionally oriented than males [64]. Thus, when they trusted their doctors, they were more likely to be satisfied. Finally, several studies revealed that physician gender can also strongly influence the physician-patient relationship [65]. Based on prior research, this paper further found that patients gender also matters in shaping the physician-patient relationship, which shows that doctorpatient relationship is more likely to be improved among male patients when they are satisfied.

5.2. Theoretical Implications. Firstly, this study revealed the mechanism of influence of accessibility to electronic appointment making on improving doctor-patient interactions. Existing studies explored the impact of information technology/hospital information system on the communication between doctors and patients [45] and the improvement of doctor-patient relationships [9]. However, most reports have been from the perspective of perceived fairness [6] and service quality [9]. Few have explored how implementation of a registered information system can enhance the mutual feelings of doctors and patients based on trust. Bending [66] pointed out that rebuilding the trust between the medical system and the public is fundamental to resolving the disputes in the current doctor-patient relationship. Therefore, based on the trust perspective, this paper analyzed the use of an online patient appointment system and uncovered a new mechanism and path between the use of an online appointment system and the improvement of doctor-patient relationships. The online appointment system can improve the doctor-patient relationship by enhancing patient transparency, trust in hospitals and doctors, and satisfaction. This research increases the knowledge foundation for how the use of an online appointment system affects patients' trust, satisfaction, and doctor-patient relationships.

Secondly, a moderating effect of gender on the use of online appointment system and the improvement of doctorpatient relationships was found. This paper examines for the first time the significant effects of gender on transparency, trust, satisfaction, and doctor-patient relationship in the use of an online appointment system. Some investigators have discussed the mechanism and path of the implementation of information technology/hospital information system for the improvement of doctor-patient relationship [43, 44]; 
however, few have discussed the boundary conditions of the hospital information system. Expanding on existing studies, this paper found that, after using the online appointment system, patients of different genders showed significant differences in perceptions of openness and transparency, trust of hospitals and doctors, satisfaction, and improvement of doctor-patient relationships. This study takes gender as a moderating variable, expands the research model of the improvement of the relationship between the use of online appointment system and the doctor-patient relationship, and enriches the research conclusion about using electronic appointment making. At the same time, it is helpful to form a more complete understanding of the relationship between the use of an online appointment and registration system for patients of different genders, patients' trust, satisfaction, and improvement of doctor-patient relationship.

5.3. Practical Implications. The tensions and conflicts between doctors and patients have seriously damaged the medical services market and the normal medical routine. Improving the relationship between doctors and patients and regaining their trust and satisfaction is essential, and the conclusions of this paper are of great significance for accomplishing this. Firstly, the hospital should actively cooperate with the deployment of "Internet + medical treatment" and actively introduce emerging information systems to facilitate patients' medical treatment. According to the research conclusion of this paper, the development of emerging technologies such as electronic appointmenting not only makes the patient's visit easier, but also enhances the patient's perception of openness and transparency which increases feelings of trust and satisfaction and hopefully better interactions with physicians. Secondly, with the development of information technology, hospitals should consider making use of Internet technology to disclose relevant medical resource information in a more timely and accurate way. Our research shows that open and transparent perception is an important factor affecting the trust of patients. At the same time, hospitals should make full use of the advantages of the Internet to provide better medical services for patients. Third, hospitals should strengthen their brand trust recognition and doctors need to do the same. According to this study, patients' trust in hospitals and doctors often affects their satisfaction. By strengthening the medical skills, ethics, and service attitudes of medical staff and strengthening the hospital's quality management, a better relationship of trust between doctors and patients can be built. Finally, the government and the hospital should work together to improve the doctor-patient relationship and build a harmonious medical environment. The government should substantially increase inputs to the medical industry, reform and improve the medical system, and guarantee the interests of medical staff and patients. Hospitals should properly guide medical staff to strengthen their professional ethics and morality, give play to the positive effects of the news media, and respect the rights of patients to know and strengthen social supervision.
5.4. Limitations and Future Research Directions. The study reported here has the following limitations: Due to time and capacity constraints, we were only able to collect 225 valid questionnaires, and future studies need to increase that number to test the research conclusions. The results of this study can also be cross-verified by interviewing and qualitative research. In addition, due to limited availability, we did not collect objective data from the internal background of the hospital. Future research can verify the conclusions of this paper by obtaining objective data from the hospitals' information system background. Third, this paper does not consider the impact of perceived fairness, doctor-patient communication, physician gender, and other factors on the doctor-patient relationship. In future research, these additional factors can be included in the model to determine how they interact with doctor-patient relationships. Finally, as the online appointment system allows patients to select doctors in the system, it may affect the allocation of medical resources to some extent. Exploring how the use of online reservation registration system affects the allocation of medical resources is worthy of future research.

\section{Data Availability}

The data used to support the findings of this study are available from the corresponding author upon request.

\section{Conflicts of Interest}

The authors declare no conflicts of interest.

\section{Acknowledgments}

This work was supported by the Key Research and Development Program of Shandong Province of China under project no. 2019GSF108222, Social Science Planning Research Project of Shandong Province under project nos. 20CJJJ21 and 19CDNJ06, Social Science Popularization and Application Research Project of Shandong Province under project no. 2020-SKZZ-67, and Statistics Research Project of Shandong Province under project no. KT1920.

\section{References}

[1] S. Guo, X. Guo, X. Zhang, and D. Vogel, "Doctor-patient relationship strength's impact in an online healthcare community," Information Technology for Development, vol. 24, no. 2, pp. 1-22, 2018.

[2] CNNIC, China Internet development report, 2018.

[3] D. A. Kenny, W. Veldhuijzen, T. V. D. Weijden et al., "Interpersonal perception in the context of doctor-patient relationships: a dyadic analysis of doctor-patient communication," Social Science \& Medicine, vol. 70, no. 5, pp. 763-768, 2010.

[4] E. S. Lazarus, "Theoretical considerations for the study of the doctor-patient relationship: implications of a perinatal study," Medical Anthropology Quarterly, vol. 2, no. 1, pp. 34-58, 1988.

[5] K. Hulme, J. Chilcot, and M. A. Smith, "Doctor-patient relationship and quality of life in Irritable Bowel Syndrome: an exploratory study of the potential mediating role of illness 
perceptions and acceptance," Psychology Health \& Medicine, vol. 23, no. 6, pp. 1-11, 2018.

[6] C. Liang, D. Gu, F. Tao, H. K. Jain, Y. Zhao, and B. Ding, "Influence of mechanism of patient-accessible hospital information system implementation on doctor-patient relationships: a service fairness perspective," Information \& Management, vol. 54, no. 1, pp. 57-72, 2017.

[7] E. J. Speedling and D. N. Rose, "Building an effective doctorpatient relationship: from patient satisfaction to patient participation," Social Science \& Medicine, vol. 21, no. 2, pp. 115-120, 1985.

[8] S. Vick and A. Scott, "Agency in health care. Examining patients' preferences for attributes of the doctor-patient relationship," Journal of Health Economics, vol. 17, no. 5, pp. 587-605, 1998.

[9] V. Venkatesh, X. Zhang, and T. A. Sykes, ““Doctors do too little technology": a longitudinal field study of an electronic healthcare system implementation," Information Systems Research, vol. 22, no. 3, pp. 523-546, 2011.

[10] C. Martins, T. Oliveira, and A. Popovič, "Understanding the Internet banking adoption: a unified theory of acceptance and use of technology and perceived risk application," International Journal of Information Management, vol. 34, no. 1, pp. 1-13, 2014.

[11] D. Kirk and R. Pine, "Research in hospitality systems and technology," International Journal of Hospitality Management, vol. 17, no. 2, pp. 203-217, 1998.

[12] C. Suess and M. Mody, "Hospitality healthscapes: a conjoint analysis approach to understanding patient responses to hotel-like hospital rooms," International Journal of Hospitality Management, vol. 61, pp. 59-72, 2017.

[13] A. Pizam, "The internet of things (IoT): the next challenge to the hospitality industry," International Journal of Hospitality Management, vol. 62, pp. 132-133, 2017.

[14] F. E. Six, "Building interpersonal trust within organizations: a relational signalling perspective," Journal of Management \& Governance, vol. 11, no. 3, pp. 285-309, 2007.

[15] N. G. Noorderhaven, "National culture and the development of trust: the need for more data and less theory," Academy of Management Review, vol. 24, no. 1, pp. 9-10, 1999.

[16] R. C. Mayer, J. H. Davis, and F. D. Schoorman, "An integrative model of organizational trust," Academy of Management Review, vol. 20, no. 3, pp. 709-734, 1995.

[17] R. Pennington, H. D. Wilcox, and V. Grover, "The role of system trust in business-to-consumer transactions," Journal of Management Information Systems, vol. 20, no. 3, pp. 197-226, 2003.

[18] G. Zhang, L. Ma, and X. Zhang, “Understanding users' recommendation intention of taxi-hailing apps: an internal perception perspective," in Proceedings of the Sixteenth Wuhan International Conference on E-Business, pp. 232-240, Wuhan, China, May 2017.

[19] M.-H. Hsu, C.-M. Chang, K.-K. Chu, and Y.-J. Lee, "Determinants of repurchase intention in online group-buying: the perspectives of DeLone \& McLean IS success model and trust," Computers in Human Behavior, vol. 36, no. 36, pp. 234-245, 2014.

[20] P. Rhodes, S. Campbell, and C. Sanders, "Trust, temporality and systems: how do patients understand patient safety in primary care? A qualitative study," Health Expectations, vol. 19, no. 2, pp. 253-263, 2016.

[21] H. Han and J. Hwang, "Multi-dimensions of the perceived benefits in a medical hotel and their roles in international travelers' decision-making process," International Journal of Hospitality Management, vol. 35, pp. 100-108, 2013.

[22] H.-C. Weng, "Does the physician's emotional intelligence matter?" Health Care Management Review, vol. 33, no. 4, pp. 280-288, 2008.

[23] J. Hou and M. Shim, "The role of provider-patient communication and trust in online sources in Internet use for healthrelated activities," Journal of Health Communication, vol. 15, no. 3, pp. 186-199, 2010.

[24] H. Yang, X. Guo, and T. Wu, "Exploring the influence of the online physician service delivery process on patient satisfaction," Decision Support Systems, vol. 78, pp. 113-121, 2015.

[25] H. Ahmadi, M. Nilashi, L. Shahmoradi et al., "The moderating effect of hospital size on inter and intra-organizational factors of Hospital Information System adoption," Technological Forecasting and Social Change, vol. 134, pp. 124-149, 2018.

[26] M.-Y. Chang, C. Pang, J. Michael Tarn, T.-S. Liu, and D. C. Yen, "Exploring user acceptance of an e-hospital service: an empirical study in Taiwan," Computer Standards \& Interfaces, vol. 38, no. 5, pp. 35-43, 2015.

[27] P. W. Handayani, A. N. Hidayanto, A. A. Pinem, I. C. Hapsari, P. I. Sandhyaduhita, and I. Budi, "Acceptance model of a hospital information system," International Journal of Medical Informatics, vol. 99, pp. 11-28, 2017.

[28] B. Rawlins, "Give the emperor a mirror: toward developing a stakeholder measurement of organizational transparency," Journal of Public Relations Research, vol. 21, no. 1, pp. 71-99, 2008.

[29] S. Grimmelikhuijsen, G. Porumbescu, B. Hong, and T. Im, "The effect of transparency on trust in government: a crossnational comparative experiment," Public Administration Review, vol. 73, no. 4, pp. 575-586, 2013.

[30] A. Knopf, "Price transparency in healthcare: a movement takes hold," Behavioral Healthcare, vol. 34, no. 3, pp. 42-43, 2014.

[31] A. Schnackenberg, "Organizational transparency: a new perspective on managing trust in organization-stakeholder relationships," Journal of Management, vol. 42, no. 7, pp. 1784-1810, 2015.

[32] Y. Yang and Y. Hou, "Is transparency a double-edged sword in citizen satisfaction with public service? Evidence from China's public healthcare," Journal of Service Theory and Practice, vol. 28, no. 4, pp. 484-506, 2015.

[33] C. Campanale, L. Cinquini, and A. Tenucci, "Time-driven activity-based costing to improve transparency and decision making in healthcare," Qualitative Research in Accounting \& Management, vol. 11, no. 11, pp. 165-186, 2014.

[34] S. M. Norman, B. J. Avolio, and F. Luthans, "The impact of positivity and transparency on trust in leaders and their perceived effectiveness," The Leadership Quarterly, vol. 21, no. 3, pp. 350-364, 2010.

[35] M. E. Palanski, S. S. Kahai, and F. J. Yammarino, “Team virtues and performance: an examination of transparency, behavioral integrity, and trust," Journal of Business Ethics, vol. 99, no. 2, pp. 201-216, 2011.

[36] G. A. Auger, "Trust me, trust me not: an experimental analysis of the effect of transparency on organizations," Journal of Public Relations Research, vol. 26, no. 4, pp. 325-343, 2014.

[37] S. Zheng, S. F. Hui, and Z. Yang, "Hospital trust or doctor trust? A fuzzy analysis of trust in the health care setting," Journal of Business Research, vol. 78, pp. 217-225, 2017.

[38] L. Choongki, H. J. Song, L. Hyemi, L. Seoki, and B. J. Bernhard, "The impact of CSR on casino employees' organizational trust, job satisfaction, and customer 
orientation: an empirical examination of responsible gambling strategies," International Journal of Hospitality Management, vol. 33, no. 1, pp. 406-415, 2013.

[39] K. Namasivayam and P. Guchait, "The role of contingent selfesteem and trust in consumer satisfaction: examining perceived control and fairness as predictors," International Journal of Hospitality Management, vol. 33, no. 1, pp. 184-195, 2013.

[40] H.-C. Wu, T. Li, and M.-Y. Li, "A study of behavioral intentions, patient satisfaction, perceived value, patient trust and experiential quality for medical tourists," Journal of Quality Assurance in Hospitality \& Tourism, vol. 17, no. 2, pp. 114-150, 2016.

[41] E. A. Platonova, K. N. Kennedy, and R. M. Shewchuk, "Understanding patient satisfaction, trust, and loyalty to primary care physicians," Medical Care Research and Review, vol. 65, no. 6, pp. 696-712, 2008.

[42] Z. Shewchuk, D. Gursoy, and B. Sharma, "Role of trust, emotions and event attachment on residents' attitudes toward tourism," Tourism Management, vol. 63, pp. 426-438, 2017.

[43] D. M. Weiner and P. Biondich, "The influence of information technology on patient-physician relationships," Journal of General Internal Medicine, vol. 21, no. 1, pp. 35-39, 2006.

[44] B. Lo and L. Parham, "The impact of web 2.0 on the doctorpatient relationship," Journal of Law, Medicine \& Ethics, vol. 38, no. 1, pp. 17-26, 2010.

[45] M. Kirshner, "The role of information technology and informatics research in the dentist-patient relationship," Convulsive Therapy, vol. 12, no. 3, pp. 138-146, 2003.

[46] L. Alrubaiee and F. Alkaa'Ida, “The mediating effect of patient satisfaction in the patients' perceptions of healthcare quality-patient trust relationship," International Journal of Marketing Studies, vol. 3, no. 1, pp. 236-254, 2011.

[47] H. Skirbekk, A.-L. Middelthon, P. Hjortdahl, and A. Finset, "Mandates of trust in the doctor-patient relationship," Qualitative Health Research, vol. 21, no. 9, pp. 1182-1190, 2011.

[48] M. Faezipour and S. Ferreira, "A system dynamics perspective of patient satisfaction in healthcare," Procedia Computer Science, vol. 16, no. 1, pp. 148-156, 2013.

[49] D. Gefen, E. Karahanna, and D. W. Straub, "Trust and TAM in online shopping: an integrated model," MIS Quarterly, vol. 27, no. 1, pp. 51-90, 2003.

[50] D. H. Mcknight, V. Choudhury, and C. Kacmar, "Developing and validating trust measures for e-commerce: an integrative typology," Information Systems Research, vol. 13, no. 3, pp. 334-359, 2002.

[51] C. S. Chang, S. Y. Chen, and Y. T. Lan, "Service quality, trust, and patient satisfaction in interpersonal-based medical service encounters," BMC Health Services Research, vol. 13, no. 1, pp. 22-33, 2013.

[52] M. Keil, B. C. Y. Tan, K.-K. Wei, T. Saarinen, V. Tuunainen, and A. Wassenaar, "A cross-cultural study on escalation of commitment behavior in software projects," Mis Quarterly, vol. 24, no. 2, pp. 299-325, 2000.

[53] Ma Liang, X. Zhang, and X. Y. Ding, "Social media users' share intention and subjective well-being: an empirical study based on WeChat," Online Information Review, vol. 42, no. 6, pp. 784-801, 2018.

[54] L. Ma, X. Zhang, X. Ding, and G. Wang, "Bike sharing and users' subjective well-being: an empirical study in China," Transportation Research Part A: Policy and Practice, vol. 118, pp. 14-24, 2018.
[55] G. Bansal, F. M. Zahedi, and D. Gefen, "The impact of personal dispositions on information sensitivity, privacy concern and trust in disclosing health information online," Decision Support Systems, vol. 49, no. 2, pp. 138-150, 2010.

[56] C. R. Li, E. Zhang, and J. T. Han, “Adoption of online followup service by patients: an empirical study based on the elaboration likelihood model," Computer in Human Behavior, vol. 114, Article ID 106581, 2021.

[57] H. Krasnova, N. F. Veltri, N. Eling, and P. Buxmann, "Why men and women continue to use social networking sites: the role of gender differences," The Journal of Strategic Information Systems, vol. 26, no. 4, pp. 261-284, 2017.

[58] V. Venkatesh, J. B. Windeler, J. B. Windeler, K. M. Bartol, and I. O. Williamson, "Person-organization and person-job fit perceptions of new IT employees: work outcomes and gender differences," Mis Quarterly, vol. 41, no. 2, pp. 525-558, 2017.

[59] J. Simićević, N. Milosavljević, and V. Djoric, "Gender differences in travel behaviour and willingness to adopt sustainable behaviour," Transportation Planning \& Technology, vol. 39, no. 5, pp. 1-11, 2016.

[60] R. Riedl, M. Hubert, and P. Kenning, "Are there neural gender differences in online trust? An fMRI study on the perceived trustworthiness of eBay offers," Mis Quarterly, vol. 34, no. 2, pp. 397-428, 2010.

[61] J. Kim, "An extended technology acceptance model in behavioral intention toward hotel tablet apps with moderating effects of gender and age," International Journal of Contemporary Hospitality Management, vol. 28, no. 8, pp. 1535-1553, 2016.

[62] A. Patiar and L. Mia, “The effect of subordinates' gender on the difference between self-ratings, and superiors' ratings, of subordinates' performance in hotels," International Journal of Hospitality Management, vol. 27, no. 1, pp. 53-64, 2008.

[63] M. V. Lecturer, "Gender differences in the prevalence and clustering of multiple health risk behaviours in young adults," Journal of Advanced Nursing, vol. 72, no. 9, pp. 2098-2113, 2016.

[64] H. T. Middendorp, R. Geenen, M. Sorbi et al., "Gender differences in emotion regulation and relationships with perceived health in patients with rheumatoid arthritis," Women Health, vol. 42, no. 1, pp. 75-97, 2005.

[65] D. L. Roter and J. A. Hall, "Why physician gender matters in shaping the physician-patient relationship," Journal of Women's Health, vol. 7, no. 9, pp. 1093-1097, 1998.

[66] Z. J. Bending, "Reconceptualising the doctor-patient relationship: recognising the role of trust in contemporary health care," Journal of Bioethical Inquiry, vol. 12, no. 2, pp. 189-202, 2015. 